\title{
Comparison of selected processes for surface microstructuring of complex mould for an implanted device
}

\section{Zhang, Yang; Hansen, Hans Nørgaard; Bissacco, Giuliano; Biondani, Francesco Giuseppe}

\section{Published in:}

International Journal of Advanced Manufacturing Technology

Link to article, DOI:

$10.1007 / \mathrm{s} 00170-018-2152-1$

Publication date:

2018

Document Version

Peer reviewed version

Link back to DTU Orbit

Citation (APA):

Zhang, Y., Hansen, H. N., Bissacco, G., \& Biondani, F. G. (2018). Comparison of selected processes for surface microstructuring of complex mould for an implanted device. International Journal of Advanced Manufacturing Technology, 97(5-8), 2741-2748. https://doi.org/10.1007/s00170-018-2152-1

\section{General rights}

Copyright and moral rights for the publications made accessible in the public portal are retained by the authors and/or other copyright owners and it is a condition of accessing publications that users recognise and abide by the legal requirements associated with these rights.

- Users may download and print one copy of any publication from the public portal for the purpose of private study or research.

- You may not further distribute the material or use it for any profit-making activity or commercial gain

- You may freely distribute the URL identifying the publication in the public portal 


\title{
Comparison of selected processes for surface micro structuring of complex mould for an implanted device
}

Key words: micro structured surface, free form, laser, nano structure, 3D product, injection moulding

Yang Zhang*, Hans Nørgaard Hansen, Giuliano Bissacco, Francesco Biondani

Department of Mechanical Engineering, Technical University of Denmark

Produktionstorvet, Building 427A, Kgs. Lyngby, DK 2800 Denmark

*Yang Zhang (ORCID 0000-0002-0883-8233)

Senior researcher,Ph.D

Email: yazh@mek.dtu.dk

Phone: 004545254892

\begin{abstract}
Polymer products with functional surfaces are applied in many fields such as medical devices and biotechnology. However, most technologies for the fabrication of micro-structured functional surfaces are still limited to flat geometries or geometries with constant curvature. This paper describes and compares three approaches for fabricating micro- or nano- structured surfaces; those process chains are suitable for patterning of the surface of 3D shape cavity for injection moulding. The desired surface features have been approved by cell proliferation test. The first approach is to use pre-fabricated plate with micro-structured surface as an inserts inside the cavity. The second approach is to directly pattern the surface by a femtosecond laser combined with mask projection technique. The third approach is to produce the cavity part using an anodizing process followed by metal deposition, and in this way, sub-micro features were obtained all over the cavity surface. The aim of this paper is to find solutions to implementing the desired features on the entire the surfaces of a 3D shaped ring; this research will also benefit the production of other complex parts with functional micro- or nano- structured surface.
\end{abstract}

\section{Introduction}

Polymer products with functional surfaces are applied in many fields such as medical and bio technology ${ }^{1 \& 2}$. It is believed that certain types of micro- or nano- structured surfaces can enhance tissue anchoring ${ }^{3456789}$, though in some cases subsequent treatments such as exposure to plasma are needed ${ }^{10}$. 
There are multiple reports on fabricating microstructures on a surface of mould for polymer injection moulding or for replication by other materials ${ }^{3}$. Most of the work focuses on flat surfaces or surfaces with a constant curvature. For instance $\mathrm{H}$. Kim et. al. has reported using micro-abrasive jet to fabricate microstructure on a curved surface with the aid of a mask ${ }^{4}$. A process for structuring a surface with a constant curvature by implementing a cylinder processing system ${ }^{11}$ was reported by S. Bruening et. al.. M.P. Rao et. al. has described a method for microfabrication of high aspect ratio structures using mask, however the structuring is limited on the projection of the pattern profile into the third dimension, i.e. it is a so-called two and half dimensional machining. $\mathrm{K}$ Mielonen et. al has reported a process chain to create hierarchically micro structure on curved surface based on bending a pre-fabricated aluminium foil with micro features ${ }^{12}$. Additive manufacturing using metal allows mould fabrication of complex geometry, however the resolution and precision for the surface feature cannot be achieved for or it does not meet the tolerance when the surface features are in micro range ${ }^{13}$. The soft-tooling process has been reported by Y. Zhang et. al. ${ }^{14}$; Polymer additive manufacturing is used for producing the mould inserts, and this approach allows micro features on surface, however due to the issue of tool life this process is only applicable for pilot production.

Typically, products that need micro structuring on the surface have a three dimensional and complex geometry. There are huge demands for investigation in establishing the microstructures on the surface of a 3D mould. The investigated demonstrator in this paper is a part of a fixture for electrodes to be implanted inside human body. It is a ring with four wings as illustrated by Fig. 1. In order to proliferate cell growth, microstructures are needed on the entire surface, or as a minimum on both sides of the wings.

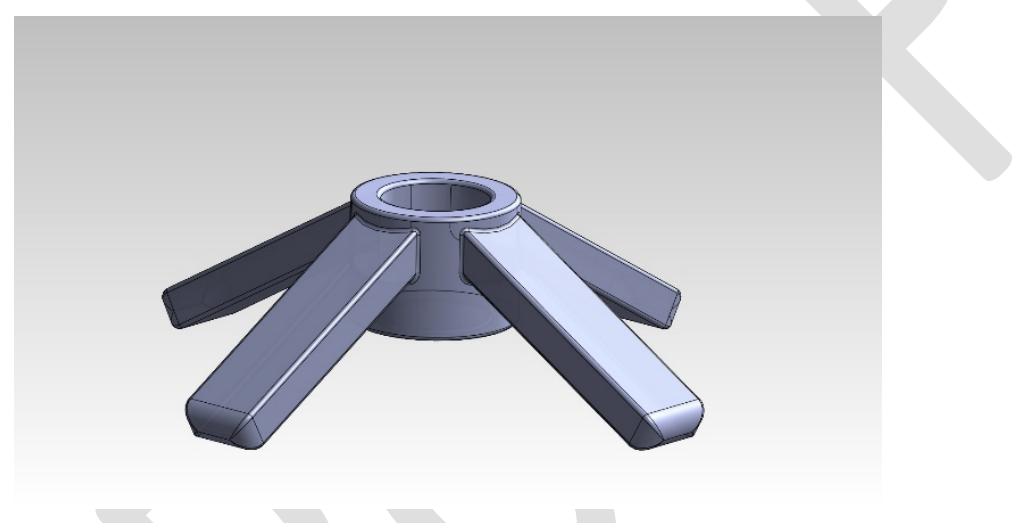

Fig. $1 \mathrm{~A}$ ring with four wings is the target product to be produced by polymer injection moulding. The overall dimension is approximately $7 \mathrm{~mm}$. The wings have an angle of $\mathbf{3 0}$ degrees from the ground. It is a fixture for an electrode implanted inside human body. The application requires micro features to be applied on the entire surface, i.e. the surface of the wings, and the external surface of the ring.

Cell proliferation tests were carried out to assess the effect of different microstructures on cell growth. A number of different surfaces were tested and the results are shown in Fig. 3. Two particular types of surfaces structures stand out because they seem to give results similar to the reference surface. This paper describes the possible process chains related to realization of these types of microstructures, and a comparison between the different process chains in terms of process characteristics as well as obtainable quality is carried out. 


\section{Process chain overview}

Three process chains are investigated in this study. The first one is based on a traditional MEMS based micro-structuring approach where a flat wafer is structured with a regular array of holes (nominal diameter of $4 \mu \mathrm{m}$ and depth of $2 \mu \mathrm{m}$ ). Then the wafer is cut into smaller pieces and these pieces used as inserts in the 3D mould cavity. The second process chain is based on a direct laser machining of holes into a tool steel surface using a femtosecond laser combined with mask projection technique. The third process chain is based on an anodized aluminium surface that is replicated using nickel electroplating. In this way, closedpacked hexagonal bumps in sub-micro scale were achieved. Error! Reference source not found. illustrates the three different process chains under investigation.

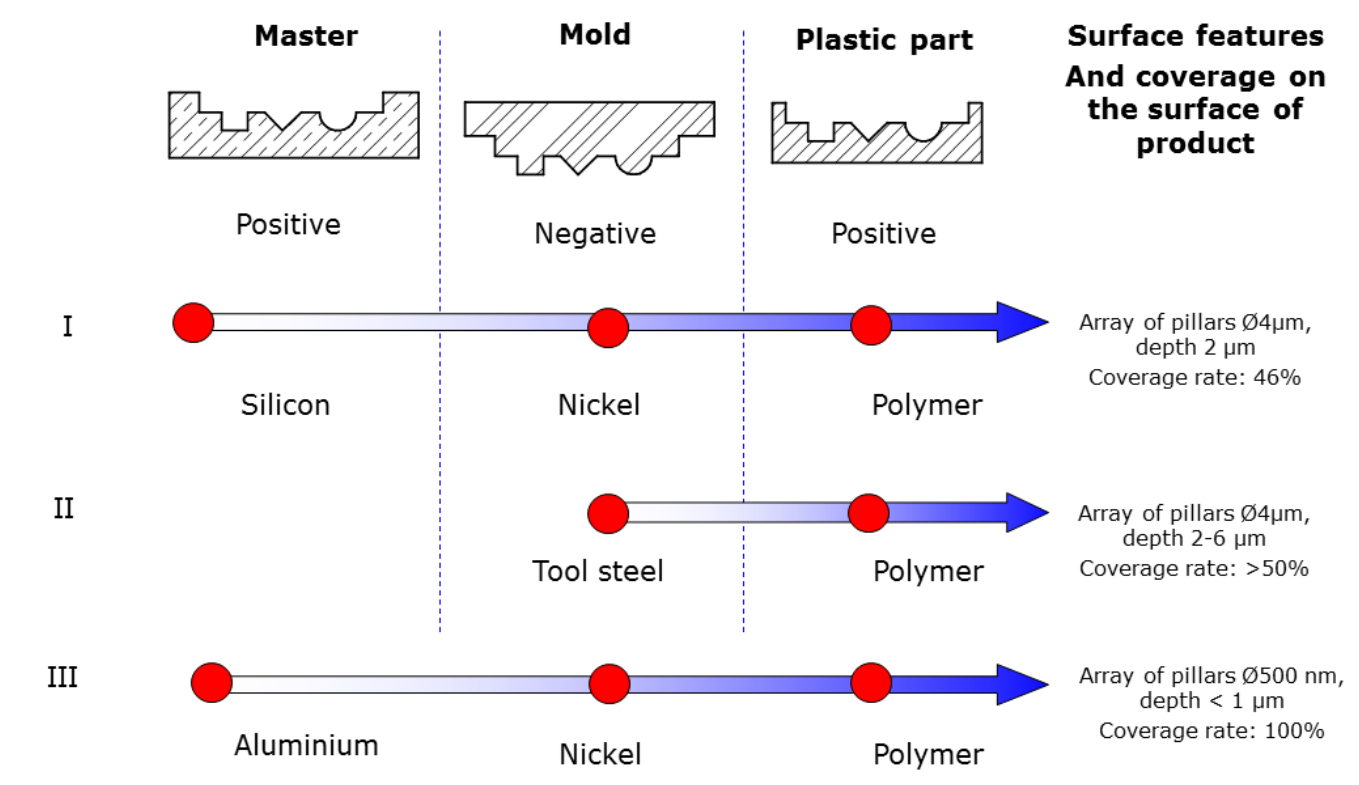

Figure 2Illustration of the three process chains investigated in this paper 


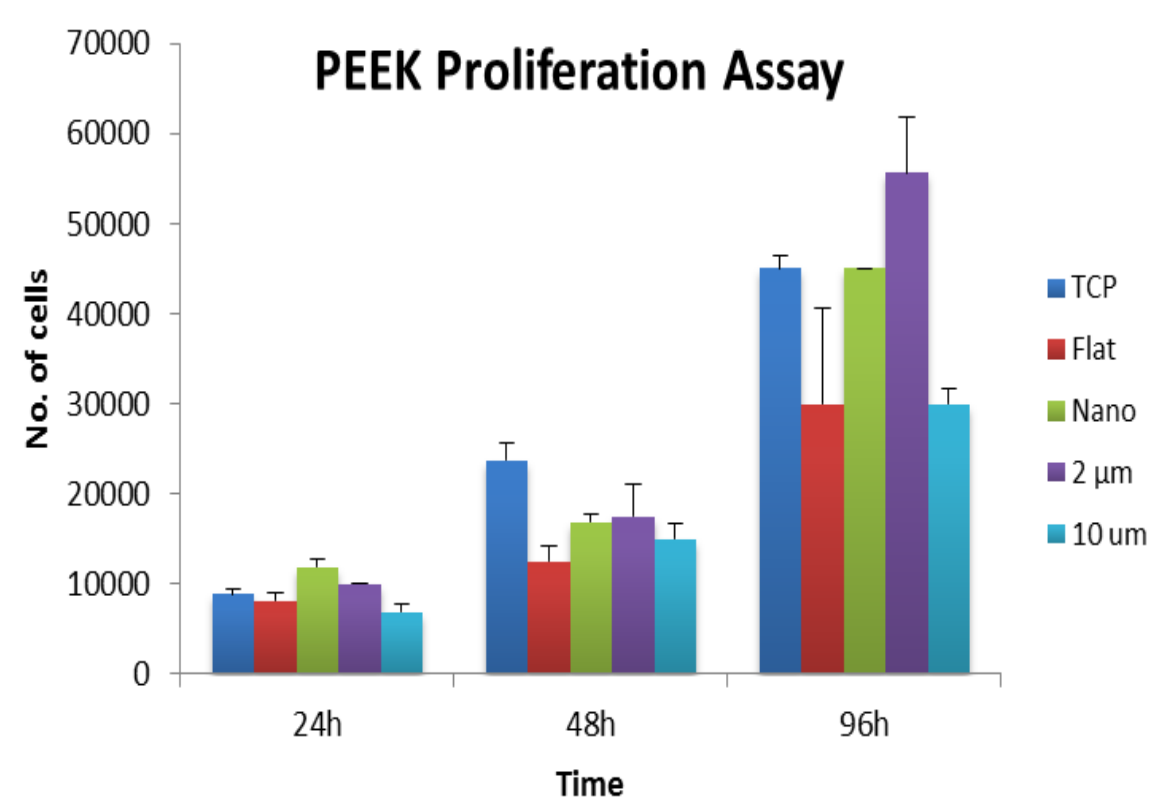

Fig. 3 Proliferation test of several micro /sub-micro structures using PEEK substrate. "TCP" refers to tissue culture polystyrene which is used as reference for the comparison. " $2 \mu \mathrm{m}$ " is the periodical 2 - $\mu \mathrm{m}$-high pillars produced by the pre-fabricated Ni inserts; "Nano" is the hexagonal bumps produced by anodizing process. Compared to the flat surface and 10- $\mu \mathrm{m}$-high pillars, the first mentioned two were suitable candidate to promote cell growth after 96 hours.

\section{Process chain 1: micro structured Ni plate machined into insert}

Approach 1 is to utilize a prefabricated nickel plate with micro structured surface as inserts for the mould cavity. The Ni plate was purchased from Hoowaki ${ }^{\circledR}$, which was fabricated by deep reactive-ion etching process process ${ }^{15}$. The dimension of the micro holes on surface are $4 \mu \mathrm{m}$ in diameter and $2 \mu \mathrm{m}$ in depth, with a $2 \mu \mathrm{m}$ edge-to-edge distance and in square lattice, as illustrated by Fig. 4.

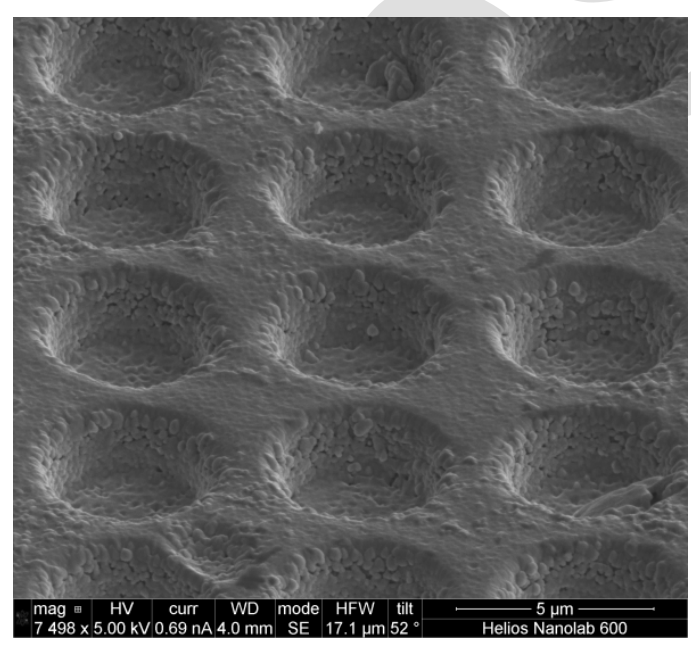

Fig. 4 Micro holes on the surface of Ni plate. The measured average hole diameter is $4.3 \pm 0.053 \mu \mathrm{m}$; the average depth of the hole is $2,11 \pm 0,025 \mu \mathrm{m}$. the surface roughness on the top is Sa $0.084 \mu \mathrm{m}$, while in the bottom of the holes is $0,154 \mu \mathrm{m}$.

The nickel plate was machined into pieces with a trapezoidal cross section; they were embedded into the cavity to form the flat sides of the wings, as illustrated by Fig. 5 . The wings have an angle of 30 degrees from 
ground. In this manner, micro-pillars were obtained on both top and bottom sides of the wings on the product. It counts for $46 \%$ of the total surface of the device.
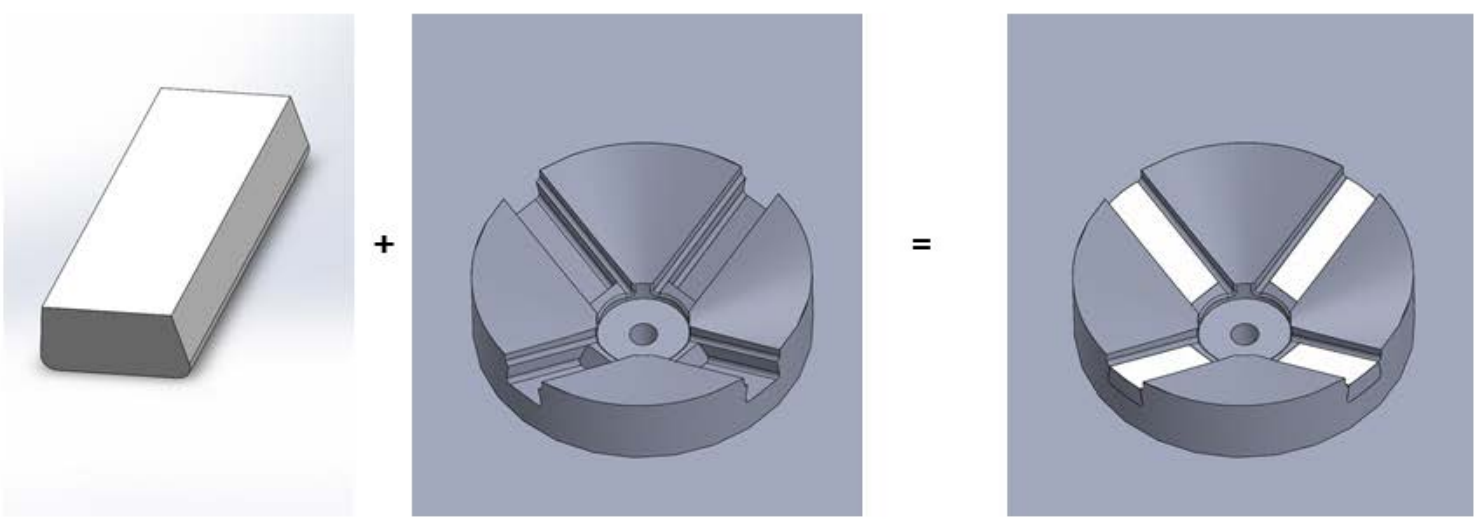

Fig. 5 Inserts made from prefabricated Ni disk are assembled with mould cavity. From left to right: the Ni piece with microstructure on the surface, cavity for the injection side and the assembly. The bright colour shows the side with micro holes.

The cavity was tested by liquid silicon rubber (LSR) injection moulding at $150^{\circ} \mathrm{C}$ for more than 1000 cycles. A FormicaPlast ${ }^{\circledast}$ (Desma ${ }^{\circledR}$, Germany) injeciton moulding machine was used. A good replication of the micro structures was achieved on both sides of the wings. No obvious wear of the tool was observed ${ }^{16}$. Fig. 6 displays the topography of the obtained pillars on silicone rubber replicas. The average height of the pillars is $1.78 \pm 0.04 \mu \mathrm{m}$; the average diameter is $3.96 \pm 0.37 \mu \mathrm{m}$.

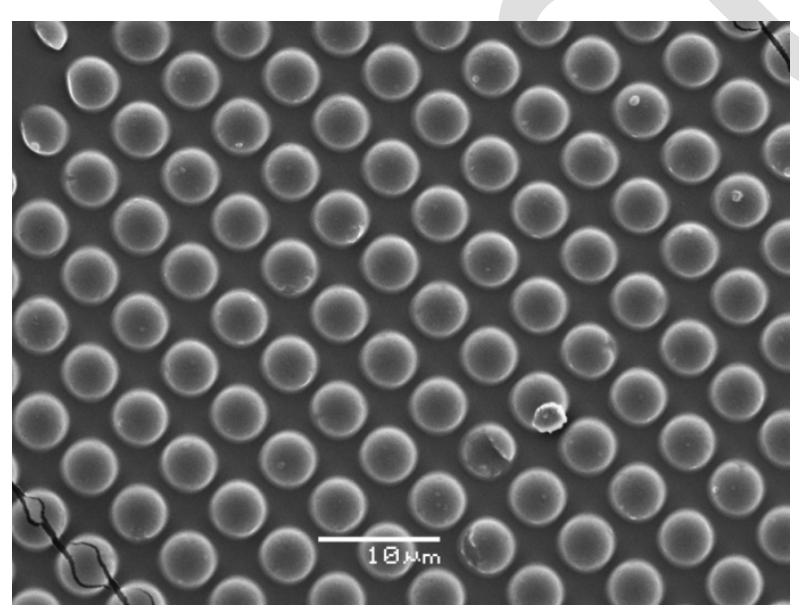

Fig. 6 Pillars obtained on silicone rubber parts by injection moulding.

There are numerous techniques for fabricating micro- or nano-structure on the surface of a metallic flat disk, so that subsequently it can be machined as inserts for injection moulding. The features can vary in dimension and pattern. Precise structuring that fulfils requirements for a micro replication can be achieved ${ }^{17}$. In the meantime, there are intensive works to investigate the replication of those features (by polymer) using injection moulding or other polymer processing techniques. It is worth to note that, when fabricating the 
nickel plate using the so-called Bosch method, a silver layer is deposited by physical vapour disposition prior to the Ni electroforming, which is necessary as seeds for Ni electroforming. The typical thickness is $200 \mathrm{~nm}$ approximately. When used in replication processes such as injection moulding, this silver layer may peel off. The Ag peeling may contaminate the polymer part if they have a medical application. Therefore protective coating can be deposited in order to protect the surface from contamination of $\mathrm{Ag}$, also it improves the demoulding of the pillars from the holes ${ }^{18}$. 1-degree draft angle is designed for the holes, in order to facilitate the demoulding process.

To machine the original disk or plate into a specific insert, depending on the materials type, facilities from a conventional mechanical workshop are needed in many cases; nowadays a wire EDM is very often used. The smaller the size of the insert, the more difficult the mounting process will be, because manual mounting will be required. Complexity of the shape will increase the difficulty too. Special clamping tools may be required for the machining. Moreover, given that the current technology for surface structuring is mainly limited on flat surface or surface with a certain curvature, the method to utilize a prefabricated plate can only be applied to flat areas in the cavity. In addition, the delivery time for the ordered plate was approximately 2 month, which must be taken into the designing cycle time. Modification on the surface pattern will lead to extra cost to re-order a new plate.

\section{Process chain 2: laser direct machining on the surface of cavity}

Approach 2 is to machine on the cavity surface by laser. Femtosecond laser and other ultra-short pulse laser sources are applied for micro machining on different materials intensively. Kuna et. al. described a method of generating grating structure inside the volume of thin silicone film by femtosecond laser direct writing ${ }^{19}$; Kling et. al. has reported metal micro drilling by femtosecond laser combined with a trepanning head, and high-aspect micro holes with high-quality sidewalls can be achieved ${ }^{20}$. As an initial test, a flat a piece of stainless steel was machined by a femtosecond Ti: Sa laser (Demtopower Compact Pro, Femtolasers Produktions $\mathrm{GMbH}$, Vienna, Austria). A flat area was prepared by EDM, so that it imitates the same surface quality as a workpiece with complex shape that is machined by the same technique. The area was handpolished by sandpaper (\#1000 and followed by \#4000) and then diamond paste. Fig. 7 shows the top view of the holes drilled by laser; on the background, scratches from polishing are visible. Fig. 8 displays a silicone replica of the holes. As can be seen the holes are circular and slightly tapered. Fig. 9 gives the dimension of the holes when varying energy and the number of laser pulses. The obtained holes are from 3 to $4 \mu \mathrm{m}$ in diameter and 2 to $8 \mu \mathrm{m}$ in depth; both the diameter and depth increase when higher pulse energy was used. The depth was also dependent on the pulse numbers. These results suggest that using the ultrashort pulse laser is able to fabricate holes array with a similar dimension and comparable repeatability $(+/-0.5 \mu \mathrm{m})$ as using lithographic methods. 

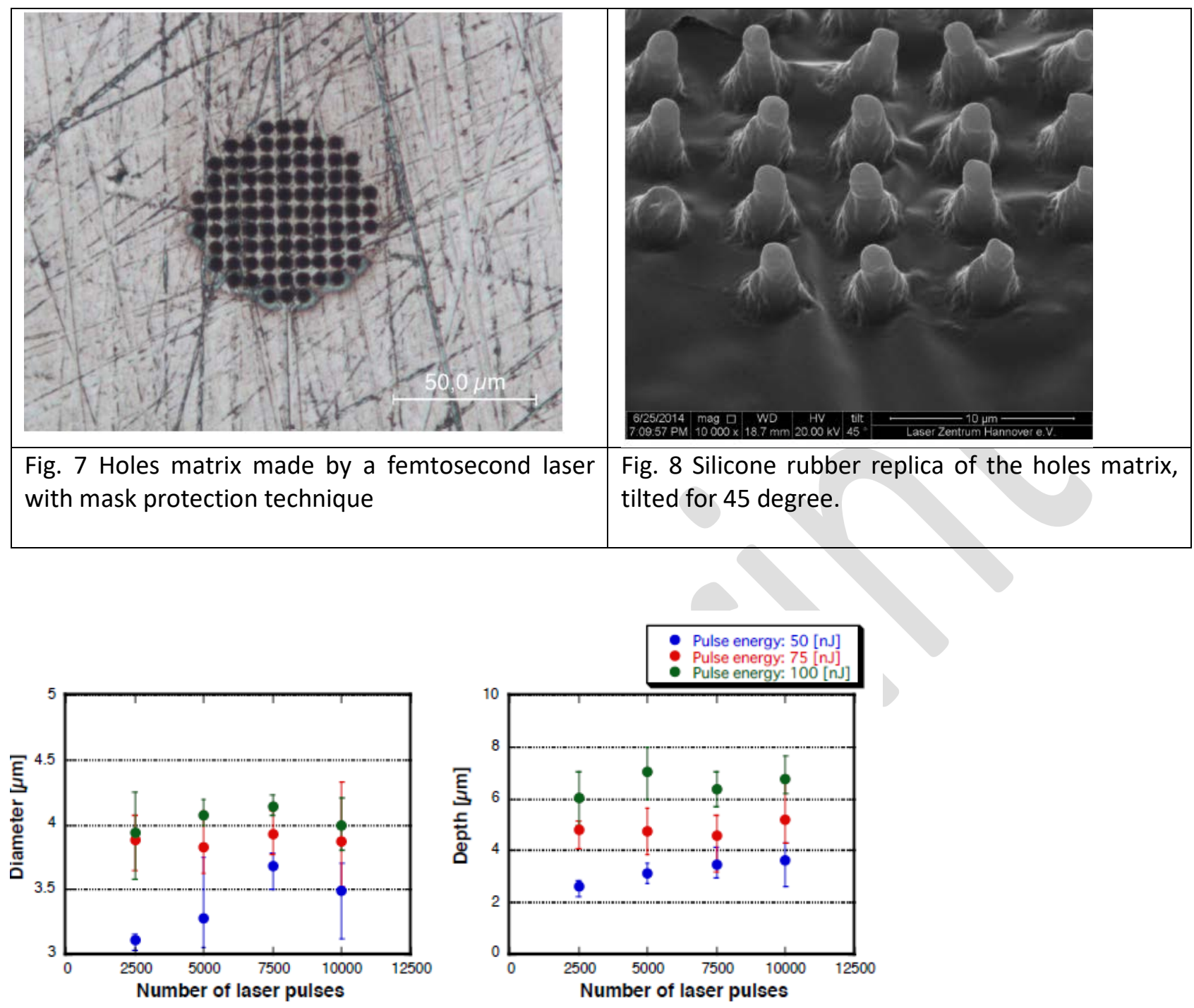

Fig. 9 The diameters and depth of the holes made by the femtosecond laser.

Laser machining has higher degree of freedom for pattern design and shorter production chain because of direct machining. It is capable to achieve features with lateral dimension from $200 \mathrm{~nm}$ to several hundred micro meters ${ }^{21}$, combined with other technology for instance mask protection or interference techniques. What is even fascinating is the possibility to machine micro features on the surface of 3D parts, although it is a line-of-sight process, i.e. only the area that laser is able to "see" can be machined; a five-axis holder will be required in order to perform the machining on surfaces with different tilting angles and achieve precise alignment. However, the production cost will be increased.

In the current research, the purpose was to create the micro holes in the comparable dimension as the Hoowaki Ni plate. The roughness of surface must be considerably smaller than the size of the desired feature (as a rule of thumb, 10\% of the size of desired features); a rough surface will lead to low repeatability. It means in order to create $2-\mu \mathrm{m}$-high features, the roughness ( $\mathrm{Ra}$ ) of the surface need to be less than $0.2 \mu \mathrm{m}$. If conventional EDM is used for cavity fabrication, which is a popular method ${ }^{22}$, the typical roughness Ra of the obtained surface is $0,8-12,5 \mu \mathrm{m}^{23}$; Then polishing is necessary. However, the size and the geometry of 
the cavity may lead to difficulties for the polishing process, since current automated polishing techniques such as electro polishing and slide grinding are based on large-area ablation. Manual polishing can be one solution; otherwise there are novel methods, for instance, laser polishing which is suitable for freeform and small area polishing can achieve roughness down to $0,01 \mu \mathrm{m}(\mathrm{Ra})$ depending on the materials type $\mathrm{e}^{24,25}$; magnetic compounds fluid combined with magnetic field can also improve the roughness to Ra below $1 \mu \mathrm{m}^{26}$. It means extra steps are required for this method, which will increase the processing time and cost.

In the studied case, mask projection technique was used in order to obtain stable machining condition at different surface qualities, combined with a microscope objective $50 \mathrm{X}$, consequently the processing time per hole was $1.0-1.5$ second. In this way approximately 8 hours is needed for machining on $1 \mathrm{~mm}^{2}$ surface. This process will be extremely time consuming and therefore expensive for the investigated tine ring mould cavity. For the investigated product, this will be a big disadvantage.

\section{Process chain 3: anodizing and etching process}

Finally yet importantly, the third approach is to use an anodizing process chain to create sub-micro structure all over the surface of the cavity.

The anodizing processing starts from anodizing of an aluminium substrate, in the shape of final product. Selforganized anodic porous alumina forms with the surface of a closed packed array of hexagonal cells. The uniform pore diameter, which is controllable by altering the anodizing conditions, can range from a few nanometres to approximately $1 \mu \mathrm{m}$. The distance between pores can also be varied by using different acid and voltage 2728 . Subsequently, the anodized layer as well as the barrier layer will be etched away by acid. Then hexagonal concaves are exposed. ${ }^{30}$

This research used aluminium alloy (Al6060) instead of pure aluminium ${ }^{31}$, due to alloy's better mechanical property, therefore complex geometry can be produced. Fig. 11 (a) and (c) show the aluminium parts. Fig. 10 (a) shows the surface structure of the aluminium after anodizing and etching. The impurities in the alloy may lead to irregular lattice; in order to remove the impurities, $1 \mu \mathrm{m}$ thick copper layer was deposited by physical vapour deposition (PVD) prior to the electroplated nickel. Nickel can also be changed to other metals to realize different functionalities ${ }^{32}$. After this step the aluminium substrate was dissolved by chemical dissolving in order to reveal the $\mathrm{Ni}$ master with the negative surface structure ${ }^{33}$. The copper layer will be etched as well and it will remove the impurities in the alloy. According to our study, the features on the $\mathrm{Ni}$ part show a good reproducibility of the aluminium surface. Additionally, the entire surface of the Ni part is structured. Then this Ni master was machined to insert for injection moulding, as shown by the right pictures in Fig. 11 (b) and (d). Fig. 10 (b) illustrates the surface of the Ni master used in our study, on which convex hexagon are closely packed. The sizes of the hexagons are approximately $420-450 \mathrm{~nm}$ in inner diameter. Replicated by polymer injection moulding was conducted initially, a distributed pattern of pores can be obtained on surfaces. 


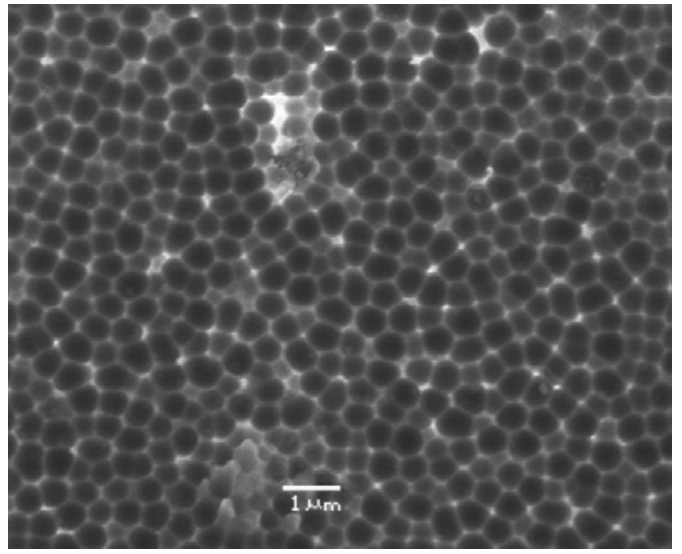

(a)

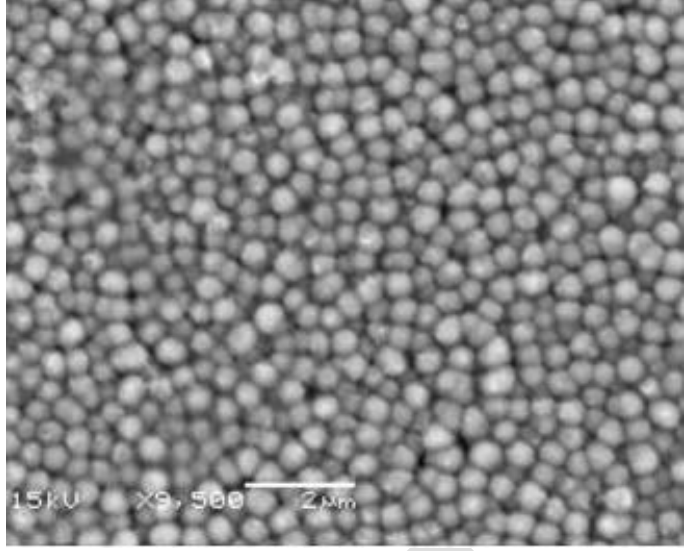

(b)

Fig. 10 (a) The surface structure of aluminium after anodizing (b) The surface structure of the nickel part after the Al was dissolved.

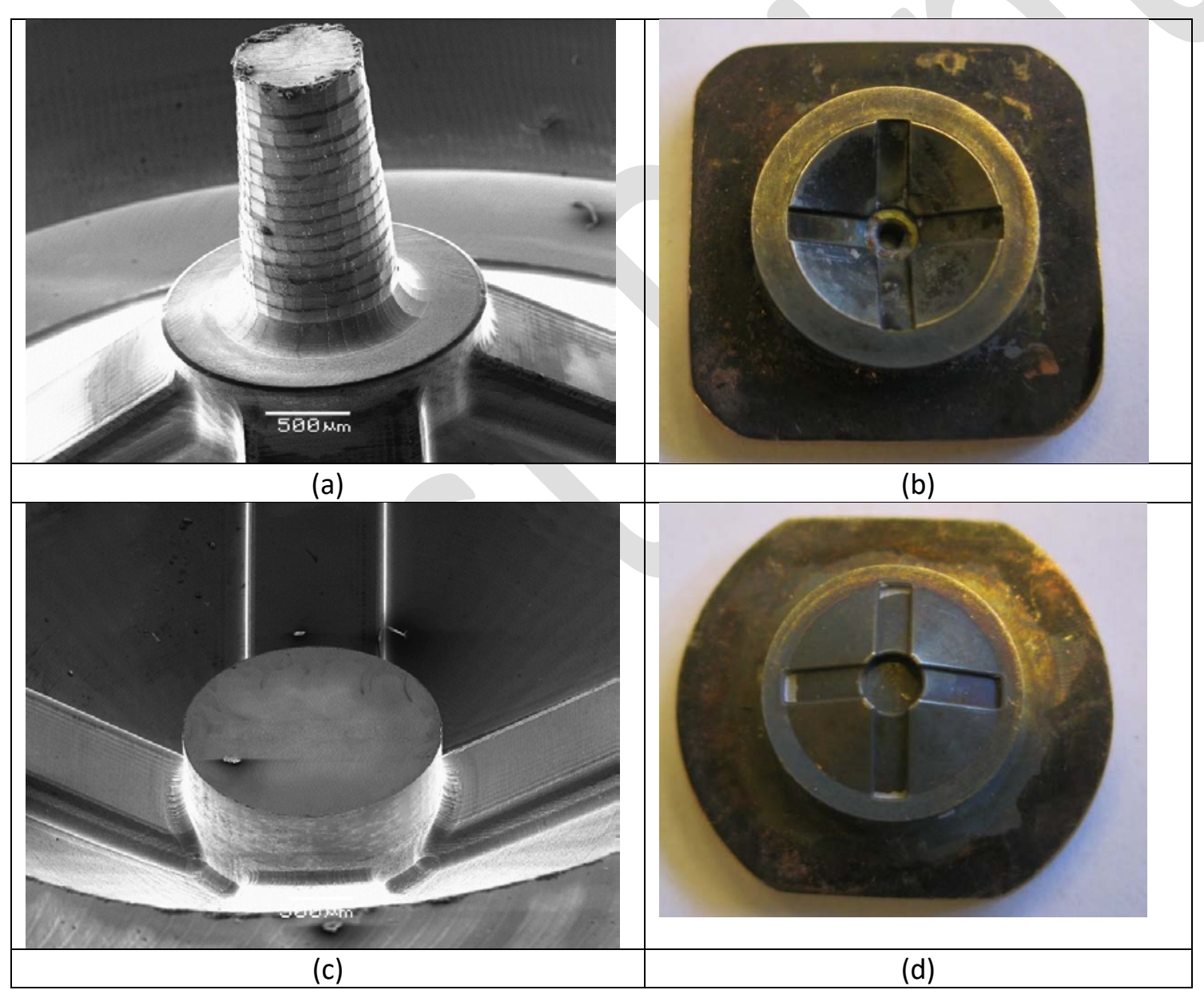

Fig. 11 (a): Aluminium part for injection side (b) Nickel part for the movable part (c) Aluminium part for the injection side (d) Nickel part for the movable side. Ni layer was electroplated on top of the Al parts (after a thin layer of copper); after the Al was dissolved, the Ni parts were machined into inserts.

Evidently, the anodizing process make it possible to create sub-micro surface structures on real 3D products. In addition, it is a relatively low cost process. The chemical treatments take from a few hours to a day. The $\mathrm{Ni}$ part formed by electroplating can achieve sufficient hardness for long-term injection moulding use. 


\section{Summary and comparison}

This paper has described 3 different process chain for establishing micro structures on a micro scale 3D geometry. The three process chains originate in different technology approaches, and therefore their capabilities were subject of this investigation.

Table 1 compares the three process chains regarding the dimensions and geometry. The first two fabricate micro holes and the third one fabricates micro bumps. The second column describes the process chain in brief. The third column illustrates the cross sections of the micro features. For micro holes, taper angle is designed to facilitate demoulding. The fourth column illustrates patterning of the features. For the method with a prefabricated plate, we define the topic within lithographical processes, such as DRIE and interference lithography; i.e. the process starts from a silicon substrate, and a mask or protective layer is required to introduce the micro features, then metal deposition or casting ${ }^{15}$ will be used to obtain the negative shape, eventually the metal part will be machined and utilized as the mould for injection moulding. These methods are capable of fabricating micro features with numerous geometries and patterns with wide range for size selection from a few nanometre to hundreds of micrometres.

The laser process can fabricate features from $200 \mathrm{~nm}$ to micrometres and above. The fifth column shows the range of the dimensions for the features generated by each method.

The anodizing process is only capable to produce hexagonal shape and highly packed pattern; the range of achievable feature size is only in sub-micro range. The lack of feature and patterning freedom may be a drawback for some applications. However, it has a huge advantage that it is able to apply sub-micro features on the entire surface.

Table 2 compares the three approaches regarding the complexity when applying those process chains. Laser machining has a wider choice for material, which makes it prior to the other two approaches. Meanwhile it is a line-of-sight process, which limit the application for real free-form machining, also polishing is required before the machining. For the other two approaches, the mould part is formed by metal deposition using wet chemistry; therefore the material is limited to metal family that can be deposited. However, anodizing process is a real free-form surface structuring method. Prefabricated plates provide enormous options for feature size and pattern, but the manufacturing cost is relatively high due to long process time. The cost to redesign the surface micro features will be very high.

With the purpose of choosing a process wisely, the requirements to the product need to be considered combined with other issues such as time, price, and availability of facilities and so on. For the current components, the first process chain was chosen for production due to the availability of the prefabricated plates.

Table 1 comparison of geometry and size of the features on mould cavity

\begin{tabular}{|c|c|c|c|c|c|c|}
\hline $\begin{array}{l}\text { Pro } \\
\text { ces } \\
\text { s } \\
\text { cha } \\
\text { in }\end{array}$ & $\begin{array}{l}\text { Descript } \\
\text { ion }\end{array}$ & $\begin{array}{l}\text { Geometry } \\
\text { Top view }\end{array}$ & $\begin{array}{l}\text { Geometry side } \\
\text { view }\end{array}$ & Pattern & $\begin{array}{l}\text { In-plane feature size }(\mu \mathrm{m}) \\
\qquad \text { capability } \quad \text { in our research }\end{array}$ & $\begin{array}{l}\text { Dime } \\
\text { nsion } \\
\text { repea } \\
\text { tabilit } \\
y\end{array}$ \\
\hline
\end{tabular}




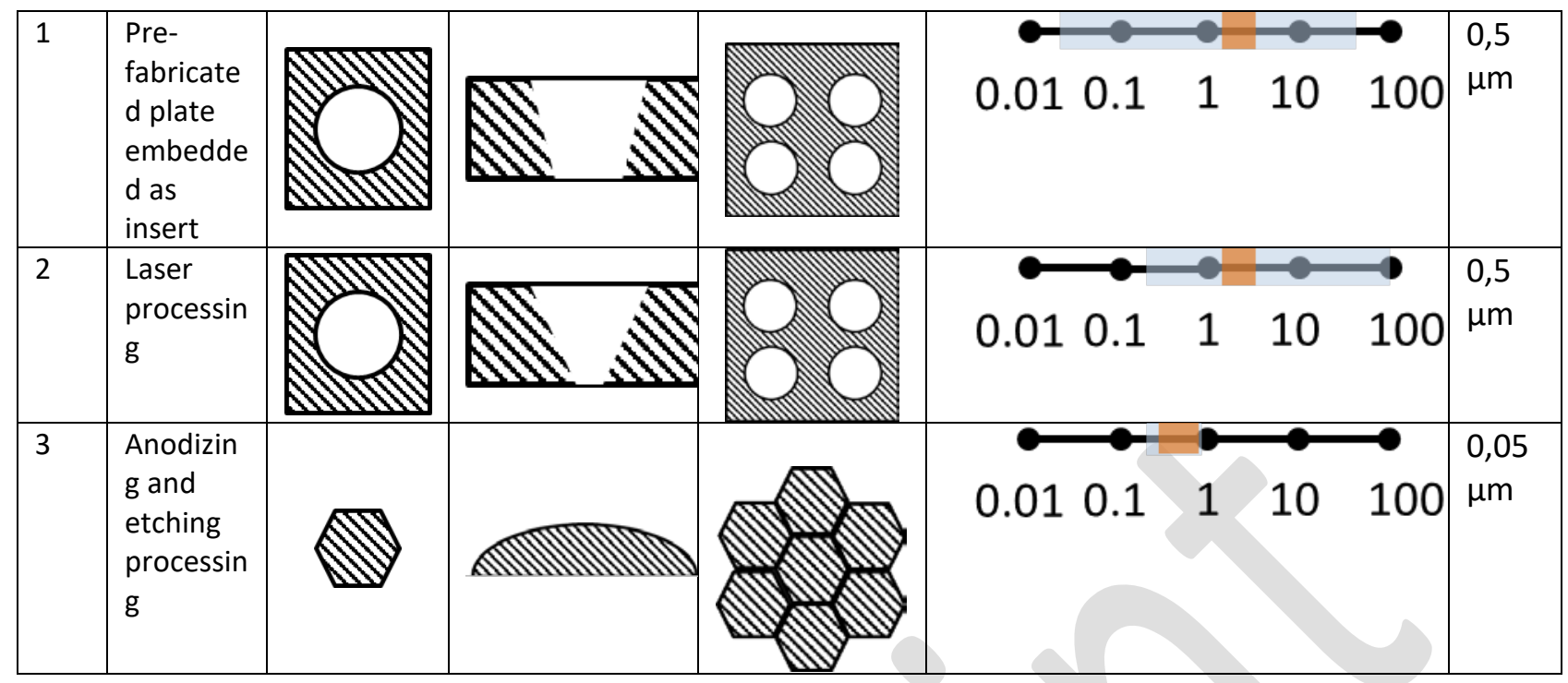

Table 2 Comparison of process complexity

\begin{tabular}{|l|l|l|l|l|}
\hline & $\begin{array}{l}\text { Feature and } \\
\text { pattern design } \\
\text { flexibility }\end{array}$ & $\begin{array}{l}\text { Fabrication time: } \\
\text { from design to } \\
\text { insert }\end{array}$ & Materials range & $\begin{array}{l}\text { Suitability for } \\
\text { Complex mould }\end{array}$ \\
\hline $\begin{array}{l}\text { Pre-fabricated plate } \\
\text { embedded as insert }\end{array}$ & High $^{34}$ & long & $\begin{array}{l}\text { Limited; Ni or } \\
\text { other plate-able } \\
\text { metal }\end{array}$ & Medium \\
\hline Laser processing & high & Short & $\begin{array}{l}\text { Wide; Metal and } \\
\text { polymer }\end{array}$ & $\begin{array}{l}\text { High (line-of- } \\
\text { sight) }\end{array}$ \\
\hline $\begin{array}{l}\text { Anodizing } \\
\text { processing }\end{array}$ & low & Long & $\begin{array}{l}\text { Limited; Ni or } \\
\text { other plate-able } \\
\text { metal }\end{array}$ & High ( free form) \\
\hline
\end{tabular}

\section{Acknowledgement}

This paper reports work undertaken in the context of the project "Advanced surface treatment for implantable medical devices" funded by Innovation Fund Denmark. The support from LZH (Laser Zentrum Hannover) and Kuz Leipzig GmBH is gratefully appreciated.

\section{Reference}

1. Doan N, Qiang L, Li Z, et al. Low-Cost Photolithographic Fabrication of Nanowires and Microfilters for Advanced Bioassay Devices. Sensors. 2015;15(3):6091-6104. doi:10.3390/s150306091.

2. Lucchetta G. Effect of injection molded micro-structured polystyrene surfaces on proliferation of MC3T3-E1 cells. Express Polym Lett. 2015;9(4):354-361. doi:10.3144/expresspolymlett.2015.33.

3. Hansen HN, Hocken RJ, Tosello G. Replication of micro and nano surface geometries. CIRP Ann Manuf Technol. 2011;60(2):695-714. doi:10.1016/j.cirp.2011.05.008.

4. Kim H, Lee I, Ko TJ. 3D tool path generation for micro-abrasive jet machining on 3D curved surface. Int J Precis Eng Manuf. 2013;14(9):1519-1525. doi:10.1007/s12541-013-0205-9. 
5. Michaeli W, Hopmann C, Schoengart M, Gillner A, Hartmann C. fabrication of micro structured 3d plastics parts by injection moulding. In: PROCEEDINGS OF THE 8TH INTERNATIONAL CONFERENCE ON MULTI-MATERIAL MICRO MANUFACTURE (4M 2011). Vol ; 2011:42-46.

6. Wilkinson CD., Riehle M, Wood M, Gallagher J, Curtis a. S. The use of materials patterned on a nano- and micro-metric scale in cellular engineering. Mater Sci Eng C. 2002;19(1-2):263-269. doi:10.1016/S0928-4931(01)00396-4.

7. Fu G, Soboyejo WO. Cell/surface interactions of human osteo-sarcoma (HOS) cells and micropatterned polydimelthylsiloxane (PDMS) surfaces. Mater Sci Eng C. 2009;29(6):2011-2018. doi:10.1016/j.msec.2009.03.017.

8. Vorobyev AY, Guo C. Femtosecond laser surface structuring of biocompatible metals. Proc SPIE - Int Soc Opt Eng. 2009;7203.

9. Tanaka Y, Satou H, Moronuki N. Microstructuring of Culture Media and its Effect on Cell Adhesion. Key Eng Mater. 2012;523-524:674-679. doi:10.4028/www.scientific.net/KEM.523-524.674.

10. Bhattacharya S, Singh RK, Mandal S, et al. Plasma Modification of Polymer Surfaces and Their Utility in Building Biomedical Microdevices. J Adhes Sci Technol. 2010;24(15-16):2707-2739. doi:10.1163/016942410X511105.

11. Bruening S, Hennig G. Surface structuring of metals and non-metals for printing tools and embossing dies with an ultrafast ps-laser machining system. In: SPIE. Vol 9351. ; 2015:935112. doi:10.1117/12.2075631.

12. K Mielonen, M Suvanto TAP. Curved hierarchically micro - micro structured polypropylene surfaces by injection molding. J Micromechanics Microengineering. 2017(27):15025. doi:10.1088/13616439/27/1/015025.

13. Muller MS, De Jean PD. 3D microscopy for microfabrication quality control. Proc SPIE - Int Soc Opt Eng. 2015;9376:937607. doi:10.1117/12.2077698.

14. Zhang Y, Pedersen DB, Gøtje AS, Mischkot M, Tosello G. Author â $€^{\mathrm{TM}}$ s Personal Copy A Soft Tooling process chain employing Additive Manufacturing for injection molding of a 3D component with micro pillars. J Manuf Process. 27:138-144. doi:10.1016/j.jmapro.2017.04.027.

15. Cannon AH, King WP. Microstructured metal molds fabricated via investment casting. J Micromechanics Microengineering. 2010;20(2):25025. doi:10.1088/0960-1317/20/2/025025.

16. Zhang $\mathrm{Y}$, Mischkot M, Hansen HN, Hansen P. Replication of microstructures on three-dimensional geometries by injection moulding of liquid silicone rubber. In: Proceedings of the 15th International Conference on Metrology and Properties of Engineering Surfaces, ASPE, American Society for Precision Engineering, . Vol ; 2015.

17. Brinksmeier E, Osmer J. Precision Mould Making - From Macro to Micro. Key Eng Mater. 2010;447448:1-8. doi:10.4028/www.scientific.net/KEM.447-448.1.

18. Zhang $\mathrm{Y}$, Hansen HN, Sørensen S. Replication of micro-pillars by PEEK injection moulding with CrNcoated Ni tool. Int J Adv Manuf Technol. 2015;80(1-4):383-388. doi:10.1007/s00170-015-6991-8.

19. Kuna L, Sommer C, Zinterl E, et al. Volume structuring of high power LED encapsulates by femtosecond laser direct writing. Appl Phys A. 2008;93(2):421-427. doi:10.1007/s00339-0084779-5.

20. Kling R, Dijoux M, Romoli L, Tantussi F, Sanabria J, Mottay E. Metal micro drilling combining high power femtosecond laser and trepanning head. 2013:86080F. doi:10.1117/12.2002083. 
21. Klein-Wiele JH, Bekesi J, Ihlemann J, Simon P. Nano-structuring with Femtosecond Excimer Laser Pulses. Excimer Laser Technol. 2005:279-283. doi:10.1007/3-540-26667-4_19.

22. Rees H. Understanding Injection Mold Design. Hanser Publishers ; Hanser Gardner Publication; 2001.

23. Black JT. Materials and Processes in Manufacturing. John Wiley \& Sons; 2008.

24. Temmler A, Willenborg E, Wissenbach K. Laser Polishing. In: Hennig G, Xu X, Gu B, Nakata Y, eds. Proceedings of Spie - the International Society for Optical Engineering. Vol 8243. ; 2012:82430W-1. doi:10.1117/12.906001.

25. Bordatchev E V., Hafiz AMK, Tutunea-Fatan OR. Performance of laser polishing in finishing of metallic surfaces. Int J Adv Manuf Technol. 2014;73(1-4):35-52. doi:10.1007/s00170-014-5761-3.

26. Sato T, Wu YB, Lin WM, Shimada K. Study of Dynamic Magnetic Field Assisted Finishing for Metal Mold Using Magnetic Compound Fluid (MCF). Key Eng Mater. 2010;447-448:258-262. doi:10.4028/www.scientific.net/KEM.447-448.258.

27. Chang $\mathrm{HL}$, Chen $\mathrm{CM}$, Sun $\mathrm{CH}$, Lin JS. Investigation of the Preparation of Anodized Nanoporous Alumina Array. Adv Mater Res. 2014;887-888:766-769. doi:10.4028/www.scientific.net/AMR.887888.766.

28. Lee W, Ji R, Gösele U, Nielsch K. Fast fabrication of long-range ordered porous alumina membranes by hard anodization. Nat Mater. 2006;5(9):741-747. doi:10.1038/nmat1717.

29. Sulka GD. Highly Ordered Anodic Porous Alumina Formation by Self-Organized Anodizing. John Wiley and Sons; 2008.

30. Tosello, Guido; Hansen, Hans Nørgaard; Tang, P.T.; Ravn, C.; Calaon M. Process chain for nano surface texture of metal and polymer micro structures. In: 10th International Workshop on High Aspect Ratio Micro and Nano System Technology. Vol ; 2013:249-250.

31. Bissacco, Giuliano; Biondani, Francesco Giuseppe; Tang, P.T.; Mischkot, Michael; Hansen, Hans Nørgaard; Zhang, Yang; Ravn C. Application of Functional Nano-Patterning to Polymer Medical Micro Implants 4M / ICOMM No . In: Proceedings of the 4M/ICOMM2015 Conference. Vol ; 2015. doi:10.3850/978-981-09-4609-8_118.

32. Tung KH, Xiang N. Fabrication of ordered metal nano-particles on a quantum well structure. 2010 Photonics Glob Conf PGC 2010. 2010:3-6.

33. Tosello G, Calaon M, Gavillet J, Tang PT, Ravn C, Tebby Z. Surface Nano Structures Manufacture Using Batch Chemical Processing Methods. In: Proceeding of the 8th International Conference on Multi-Material Micro Manufacture. Vol ; 2011:978-981. doi:10.3850/978-981-07-0319-6.

34. Yu C-C, Chen H-L. Nanoimprint technology for patterning functional materials and its applications. Microelectron Eng. 2015;132:98-119. doi:10.1016/j.mee.2014.10.015. 